\title{
O PERIGO DA INFÂNCIA: UMA ARMADILHA PARA PEGAR ADULTOS?
}

THE DANGER OF CHILDHOOD: A TRAP TO CATCH ADULTS?

EL PELIGRO DE LA INFANCIA: ¿UNA TRAMPA PARA ATRAPAR ADULTOS?

Márcia Rosa*

\begin{abstract}
RESUMO
Depois de apresentar as formulações de Michel Foucault em Os Anormais, destacando a presença do monstro judiciário, do pequeno masturbador e da criança indisciplinada na gênese da noção de anormal, e mostrando como a psiquiatria deixa de operar como uma terapêutica para exercer uma função disciplinar, a autora recorre à psicanálise de Freud e Lacan para diferenciar a criança foucaultiana e a criança freudiana, bem como a responsabilização jurídica e a responsabilização subjetiva. Para marcar os pontos de conjunção e disjunção entre Foucault e a psicanálise, o artigo faz uma apresentação e discussão teórica do tema em questão. Finaliza ao concluir que, a ter de escolher entre os dois discursos, fica com os dois, já que Foucault nos é importantíssimo para a discussão da luta antimanicomial e para uma reflexão crítica sobre questões ligadas à saúde mental, enquanto a psicanálise é indispensável como clínica.
\end{abstract}

Palavras-chave: Anormais. Foucault. Psicanálise

\begin{abstract}
After presenting Michel Foucault's formulations in The Anomalies, highlighting the presence of the judicial monster, the small masturbator and the undisciplined child in the genesis of the notion of abnormal, and showing how psychiatry ceases to operate as a therapeutic to exercise a disciplinary function, the author resorts to the psychoanalysis of Freud and Lacan to differentiate the Foucaultian child and the Freudian child, as well as legal accountability and subjective accountability. To mark the points of conjunction and disjunction between Foucault and Psychoanalysis, the article uses a theoretical presentation and discussion of the subject in question. The conclusion is that, having to choose between the two discourses, the author stays with both of them, considering that Foucault is very important for the discussion of the anti-asylum struggle and for a critical reflection on issues related to mental health, whereas psychoanalysis is indispensable as clinic
\end{abstract}

*Pós-doutora em Teoria Psicanalítica pela Universidade Federal do Rio de Janeiro (UFRJ), doutora em Literatura Comparada pela Universidade Federal de Minas Gerais (UFMG), professora na Pós-Graduação em Psicologia (UFMG), psicóloga, psicanalista, membro da Associação Mundial de Psicanálise (AMP) e da Escola Brasileira de Psicanálise (EBP). Endereço: Rua Levindo Lopes, 333, sala 503 - Savassi, Belo Horizonte-MG, Brasil. CEP: 30140-170. 
Keywords: Abnormal. Foucault. Psychoanalysis.

\section{RESUMEN}

Después de presentar las formulaciones de Michel Foucault en Los Anormales, destacando la presencia del monstruo judicial, del pequeño masturbador y del niño indisciplinado en la génesis de la noción de anormal, y mostrando cómo la psiquiatría deja de operar como una terapéutica para ejercer una función disciplinaria, la autora recurre al psicoanálisis de Freud y Lacan para diferenciar al niño foucaultiano y al niño freudiano, así como la responsabilización jurídica y la responsabilización subjetiva. Para marcar los puntos de conjunción y disyunción entre Foucault y el Psicoanálisis, el artículo hace una presentación y discusión teórica del tema en cuestión. Finaliza al concluir que, al tener que elegir entre los dos discursos, es preciso quedarse con los dos, en la medida en que Foucault nos es importantísimo para la discusión de la lucha antimanicomial y para una reflexión crítica sobre cuestiones relacionadas con la salud mental, mientras que el psicoanálisis es indispensable en cuanto clínica.

Palabras clave: Anormal. Foucault. Psicoanálisis.

\section{INTRODUÇÃO}

$\mathrm{N}$

a primeira parte deste trabalho, acompanharemos de perto as formulações de Michel Foucault em seu curso dos anos de 1974 e 1975, nas quais ele faz, com brilhantismo, a genealogia da noção de anormal, conceito que será bastante operante a partir do século XIX. Isto posto, abriremos um breve diálogo, a ser retomado posteriormente em outras publicaçôes, entre as formulaçōes apresentadas por Foucault, nesse momento de sua extensa trajetória acadêmica e de sua vasta e riquíssima produção teórica, e as formulações da psicanálise, em especial aquela de Freud e Lacan.

Nesse percurso, sinalizaremos pontos de convergência e de interesse comuns, mas também pontos de divergência e de especificidade entre os dois discursos, o da genealogia de Foucault e aquele da psicanálise lacaniana, especialmente na leitura de Lacan proposta por Jacques-Alain Miller.

\section{EM HOMENAGEM A FOUCAULT}

No seu livro, Os anormais, composto com as aulas ministradas no Collège de France nos anos de 1974 e 1975, ao fazer uma genealogia das relaçôes de poder e saber, Foucault (2010) mostra como, em meados do século XIX (1850-1870), a psiquiatria abandona a noção de doença em benefício da de comportamento, 
de seus desvios e de suas anomalias, passando a operar com o pressuposto de um desenvolvimento normativo. $\mathrm{O}$ estatuto de doença, presente em noções psicopatológicas tais como delírio, alienação mental e mesmo a referência à verdade, dá lugar ao estatuto de anomalia. Essa despatologização do objeto cria as condições para a generalização do poder e saber médico da psiquiatria, fazendo com que ela passe a operar preferencialmente como um mecanismo e instância de defesa da sociedade, ou, em termos mais contundentes, como uma caça aos anormais.

Uma vez definido como anormal, o sujeito se torna portador de um perigo e, não importa o que faça, é inacessível à pena, e, finalmente, é incurável. Ao apresentá-lo assim, Foucault resgata as três perguntas feitas aos psiquiatras que depõem nos tribunais: o indivíduo é perigoso? $\mathrm{O}$ réu é acessível à pena? $\mathrm{O}$ réu é curável? Para ele, no horizonte dessas perguntas, encontramos os resíduos da teoria da degeneração e de sua investigação da hereditariedade, da ascendência, da infância, do comportamento do indivíduo em um sentido histórico bastante preciso.

Com a teoria da degeneração, formulada por Morel, em 1857, na mesma época em que Griesinger propõe modelos neurológicos do comportamento anormal, a psiquiatria se desresponsabiliza da tarefa de curar. Ao associar qualquer desvio, anomalia, retardo, a um estado de degeneração, hereditário e definitivo, esfuma-se o projeto terapêutico, e a psiquiatria passa a intervir na sexualidade das famílias, com o álibi de estar protegendo, cientificamente, a sociedade e, biologicamente, a espécie.

Foucault assinala a presença de três figuras na genealogia do que será considerado anormal: a do monstro judiciário, a da criança indisciplinada e a do pequeno masturbador. Com o "monstro judiciário", entram em consideração noções como hereditariedade e degeneração; com a criança indisciplinada, encontramos a resistência infantil diante da lógica de controle imposta pela família e, com a figura do pequeno masturbador, abrir-se-á o campo de uma psicopatologia sexual.

Com base nessa leitura proposta por Foucault sobre os anormais, gostaria de destacar um ponto específico: o lugar da criança, ou melhor, da infância como crucial para o deslocamento da psiquiatria de uma posição terapêutica a uma posição normativa. A tese proposta é bastante original: a infância constitui uma das condições históricas da generalização do saber e do poder psiquiátricos, ela funcionará como filtro para a análise dos comportamentos. Desde aí, para psiquiatrizar uma conduta, não será mais preciso inscrevê-la no contexto de uma doença, de uma sintomatologia coerente e reconhecida, será suficiente 
que ela traga em si vestígios de infantilidade. Toma-se como princípio que os comportamentos da criança podem fixar, bloquear, deter a conduta do adulto e se reproduzir nela. Constitui-se assim, uma estrada de mão dupla: as condutas das crianças podem gerar fixações adultas e, por outro lado, ao investigar as condutas adultas será necessário verificar o que há nelas de traço de infantilidade. Em vista disso, "A infância foi, na psiquiatria como em outros domínios, a armadilha de pegar adultos" (Foucault, 2010, p. 266).

\subsection{O pequeno masturbador e o estreitamento dos laços da família conjugal}

A sexualidade da criança e do adolescente tornam-se um problema a partir do século XVIII, momento no qual o autoerotismo infantil, em outros termos, a masturbação infantil foi considerada como um perigo maior. Esse perigo foi responsável por um estreitamento dos laços na família burguesa moderna e pelo estabelecimento de um corpo a corpo entre pais e filhos, uma vez que eles foram "convocados a partir à caça dos cheiros, dos vestígios, dos indícios" (Foucault, 2010, p. 231).

A masturbação atribuída à infância se tornou objeto de uma grande cruzada no século XVIII, responsável por alguns fatos, no mínimo, pitorescos. Entre esses, a construção de um museu de cera que apresentava, por estátuas, os males aos quais estavam sujeitos aqueles que se masturbavam. Além dele, um tratado educativo, bastante popular na época, o Livro sem título, advertia quanto às consequências desastrosas da masturbação por meio da figura "decomposta, devastada, esquelética e diáfana do jovem masturbador que se esgota" (Foucault, 2010, p. 204).

Pela análise da campanha antimasturbação do século XVIII, Foucault sustenta sua discordância quanto à tese de que "no momento em que se desenvolve a sociedade capitalista, o corpo, que era até então [...] um 'órgão de prazer', se torna e deve se tornar um 'instrumento de desempenho', desempenho esse necessário às próprias exigências de produção" (Foucault, 2010, p. 205). Dois elementos invalidam a hipótese de uma causalidade econômica em última instância: o fato de a campanha antimasturbação visar a crianças e jovens, ainda não participantes do sistema de produção, e o fato de que a dita campanha incidia especificamente sobre a masturbação e não sobre a sexualidade em geral.

Foucault mostra como o pequeno masturbador se torna um dos pilares de construção da noção de anormal conforme ele dá lugar à ficção da doença total, de uma doença polimorfa, absoluta, sem remissão, acumulando em si sintomas de todas as doenças possíveis. Assim, a masturbação serve como etiologia para a 
meningite, a encefalite, a mielite e outros danos da medula espinhal, as doenças ósseas, a degeneração dos tecidos, as doenças dos olhos, as doenças cardíacas, etc. Não bastasse esse discurso médico, ancorado em uma fabulação científica, a masturbação fará surgir uma espécie de gênero literário que é a "carta do doente", uma pequena autobiografia do masturbador concentrada em seu corpo e na história de suas doenças e sensaçôes, descrita desde a infância até o momento da confissão.

Foucault localiza nessa cruzada antimasturbação o elemento determinante para a cristalização da família restrita, família que exercerá, tal como a psiquiatria normativizante da época, uma instância de poder e controle. Assim, "uma das condiçôes para coagular a família conjugal foi tornar os pais responsáveis pelo corpo dos filhos, da vida e da morte dos filhos, e isso por intermédio de um autoerotismo que tinha se tornado fabulosamente perigoso no e pelo discurso médico" (Foucault, 2010, p. 232).

\subsection{A psiquiatria e uma concepção desenvolvimentista da infância: o caso Charles Jouy}

Considerada como o ponto central em torno do qual vão se organizar os indivíduos e as condutas, a infância fará funcionar a psiquiatria

No sentido de que a neurologia do desenvolvimento e das interrupções do desenvolvimento, a biologia geral também [...] - com toda a análise que pode ser feita no nível dos indivíduos, das espécies, da evolução - tudo isso vai ser, de certo modo, a margem e a garantia no interior das quais a psiquiatria vai poder funcionar como saber cientifico e saber médico (Foucault, 2010, p. 268).

Tal como já assinalado, a infância e a infantilidade da conduta oferecem à psiquiatria não exatamente uma doença ou um estado patológico, mas um estado que, sem ser patológico, nem por isso é um modo normal. Uma vez estabelecido esse estado geral de anomalia, que não é sintoma de uma doença, construir-se-á "toda uma história desse pequeno povo de anormais", conclui Foucault (2010, p. 272).

Com o caso de Charles Jouy (personagem de irônico nome e trágica realidade), podemos acompanhar o modo como um desses anormais encontrava a psiquiatria no século XIX, mais precisamente no ano de 1867.

Trabalhador rural da região de Nancy, Jouy é denunciado ao prefeito de sua aldeia pelos pais de uma menina a quem ele teria mais ou menos violentado. Incriminado, ele é encaminhado ao grande hospício da região, no qual é examinado durante várias semanas por dois psiquiatras. Contando 40 anos no 
momento do ocorrido, Jouy é filho natural de uma mãe que morreu quando ele era bem jovem. Viveu ao deus-dará, meio à margem, pouca escolarização, meio beberrão, solitário. Em suma, ele ocupou o lugar de "idiota da aldeia" (Foucault, 2010, p. 256). A partir do interrogatório da menina, sabe-se que ele a fez masturbá-lo no mato, enquanto uma outra menina olhava. Depois disso, elas contaram, rindo, para um lavrador que passou por ali, que haviam feito coalhada com Jouy. Inscrito no espírito de uma sexualidade ao ar livre, o acontecido não gera, de início, nenhum constrangimento ao adulto que o escuta e nem mesmo qualquer consequência, observa Foucault. As meninas recebem de Jouy alguns trocados para comprar doces, não contam aos pais para não apanharem, e a vida segue. Descobre-se, inclusive, que elas já foram vistas nessa mesma prática com alguns adolescentes, e que isso é de conhecimento de toda a aldeia.

Em uma outra ocasião, Jouy arrasta a menina (ou foi arrastado por ela, indaga Foucault) para um fosso à beira da estrada e, ali, um quase estupro acontece. Uns dias depois, ao lavar a sua roupa, a mãe percebe o acontecido e o denuncia. Inserida no espírito da época, regido pelas diretrizes higiênicas e morais vigentes no século XIX, a família, no caso a mãe, faz a vistoria das roupas, modo de vigilância habitual das práticas masturbatórias das crianças: essas pequenas gozadoras!

Foucault observa que, diante desse fato que, alguns anos antes, a população da aldeia teria considerado cotidiano e sem importância, passa a vigorar uma instância de controle com ramificaçôes múltiplas, técnicas, médicas, judiciárias, etc., de modo que a menina é enviada para uma casa de correção, onde deve permanecer até sua maioridade, e o adulto ao tribunal e, depois, ao asilo psiquiátrico, onde deve permanecer indefinidamente.

À indagação jurídica se Jouy poderia ser responsabilizado por seus atos, um dos psiquiatras, em seu primeiro relatório, afirma que sim, que ele é juridicamente, judicialmente responsável, mas, à parte, em uma carta anexada ao juiz de instrução, esse mesmo psiquiatra observa que o seu senso moral "é insuficiente para resistir aos instintos animais", fazendo dele "um pobre de espírito desculpável por sua obscuridade" (Foucault, 2010, p. 257). Desse parecer, para não dizer, desse apelo médico a uma psiquiatrização, resulta o arquivamento do processo e a internação definitiva do personagem. Colocada diante da questão da responsabilização, a psiquiatria da época declara Jouy perigoso, inacessível à pena e incurável.

No que tange a seu destino psiquiátrico, Foucault observa que o exercício médico-psiquiátrico que se efetiva aí, e que vai gerar a psiquiatrização definitiva do ato, encontra seu fundamento não em uma patologização do excesso, da exacerbação dos instintos, mas na insuficiência, na falta de maturação dos 
mecanismos que regulariam os procedimentos inferiores e instintivos de satisfação: devido a uma interrupção do desenvolvimento permanece uma infantilidade. Para os laudos psiquiátricos, ele não é mau, é até meigo, mas seu senso moral está abortado; tem caráter infantil, não aprecia o valor moral de seus atos. "Nós o achamos pueril, sem consistência moral", concluem os legistas (Foucault, 2010, p. 263).

Não parece desnecessário observar com Foucault que, os elementos aventados não são convincentes como causa desencadeante do ato transgressivo em exame. No entanto, o que Jouy é agora ele já o era na infância, portanto ele está desculpado; seu processo de responsabilização subjetiva pode ser arquivado, e sua sentença psiquiátrica definitiva pode ser emitida. Inscrito em uma espécie de constelação física permanente, ele é submetido a medições de diâmetro occiptofrontal, occiptomental, etc. Constata-se, ironiza Foucault (2010), que "a boca é larga demais e que o palato apresenta uma curvatura que é característica da imbecilidade" (pp. 260-61). Esses elementos, associados ao ato, constituem um estado congênito, constitutivo, permanente, de tal sorte que é ele, esse estado, que responde pelas dismorfias do corpo e pelas anormalidades da conduta, as quais seriam suas consequências no campo instintivo.

É importante ressaltar que Foucault nos dá elementos suficientes para colocar em questão o parecer da psiquiatria forense e o diagnóstico de deficiência intelectual grave. Jouy ocupa o lugar bem conhecido do simplório, do idiota da aldeia, embora esteja bastante inserido no contexto social ao qual pertence: ele cumpre aí o papel do imigrante, ou seja, ele faz o trabalho que ninguém quer e recebe por isso não mais do que 25 por cento do que recebem os outros trabalhadores na região. Em vista disso, Foucault observa como a posição subjetiva flutuante e instável de Jouy serve bem econômica e socialmente.

Parte do diálogo registrado entre os psiquiatras e Jouy mostra-se interessante no sentido de nos permitir ir além da leitura forense, fundada em pressupostos biologizantes que excluem a subjetividade e reintroduzir o sujeito em sua história. "O que você fez desde os 14 anos? - Estive aqui, estive ali", responde. (Foucault, 2010, p. 257). "Estavam satisfeitos com você [...] na escola? Não quiseram ficar comigo." "Costumava se divertir com os outros garotos? - Eles não queriam saber de mim." $\mathrm{O}$ psiquiatra lhe pergunta por que não se dirigia às moças grandes, em vez de às garotinhas, e ele lhe responde que elas zombavam dele. Enfim, ele era rejeitado até em sua casa: "Quando você voltava [do trabalho...], o que fazia? - Ficava no estábulo” (Foucault, 2010, p. 257).

Em última instância, ocorrerá uma substituição do indivíduo juridicamente 
responsável pelo elemento correlativo de uma técnica que consiste em pôr de lado os indivíduos perigosos, em cuidar dos que são sensíveis à sanção penal, para curá-los ou readaptá-los. Apaga-se, assim, o sujeito de direito, responsável e responsabilizável por seus atos.

\section{A PSICANÁLISE, A SEXUALIDADE DA CRIANÇA E A RESPONSABILIDADE SUBJETIVA}

Ao fazer uma genealogia das relaçôes de poder e saber, Foucault sustenta que, sob o pretexto da educação e do tratamento, operou-se um movimento de normativização dos comportamentos em defesa dos interesses sociais. A propósito, ele observa que, quando se discute sobre dar educação sexual para as crianças na escola, e isso já em 1974 (data na qual o curso está sendo proferido), trata-se de uma tapeação, visto que, por trás da suposta educação, o que ocorre é um exercício de poder e controle operado por uma série de aparelhos repressores. Nos seus termos:

Faz dois séculos que nos dizem: [...] deem-nos seus filhos, e o poder de vocês sobre o corpo sexual deles, sobre o corpo de prazer, será mantido. E agora os psicanalistas começam a dizer: "A nós, a nós, o corpo de prazer das crianças!"; e o Estado, os psicólogos, os psicopatologistas, etc., dizem: "A nós, a nós, essa educação!" (Foucault, 2010, p. 224).

Portanto, sob o pretexto de construir a genealogia das relações de poder, no cerne das quais estaria a sexualidade da criança como um instrumento de troca, Foucault transforma (seria possível dizer reduz?) a família, a psiquiatria, a escola, a psicanálise, etc., em simples aparelhos repressores.

\subsection{Sobre a criança freudiana}

Diante disso, cabe lembrar que a criança foucaultiana e a sua sexualidade é bastante diferente da criança freudiana. Que, para Freud, a sexualidade infantil esteja na etiologia da neurose já diz, por si só, do caráter não tão domesticável (se me permitem o termo) da sexualidade, seja ela infantil, adolescente ou adulta. Diante dos imperativos civilizatórios, do tipo "Reprima-se! Civilize-se! Eduque-se! Trate-se!”, Freud (1929) mostrará que essas injunções superegoicas são responsáveis pelo mal-estar na civilização! Já em 1908, ele denuncia a moral sexual vigente, com suas propostas moralizantes, como causadora de doenças nervosas. Não bastasse isso para distinguir a criança foucaultiana da criança freudiana, cabe observar que, para a psicanálise, o infantil é um dos nomes do inconsciente. Nesse sentido, poderíamos perguntar, por exemplo, com quais sintomas, inibições ou angústias a menina, a pequena gozadora do caso de 
Charles Jouy, teria colocado sob esquecimento (esquecimento correspondente ao processo de recalcamento, ao qual Freud denominou amnésia infantil) aquilo que se passou na cena infantil de encontro com o gozo sexual? Nesse sentido, a sexualidade infantil e a criança freudiana são consideradas não apenas como objetos passivos diante da intervenção do Outro e de seus aparelhos repressores, mas como sujeitos capazes de levantar a voz e de se endereçarem ao Outro para dizer, de modo sintomático, se for o caso, daquilo de que elas padecem!

\subsection{A responsabilização subjetiva}

Conforme Foucault trata a questão de Os anormais pelo viés da conexão entre a Psiquiatria e o Direito, com seus exames e laudos periciais, parece-me importante dar uma palavra sobre a responsabilização subjetiva. O psicanalista Jacques-Alain Miller, em seu texto Nada é mais humano que o crime, mostra, de modo bastante convincente, que ao psicanalista não cabe "assumir responsabilidades com fins sociais", isto é, com fins de normatização. Assim, é importante distinguir como cada um dos campos, o da Psiquiatria, do Direito e da Psicanálise, considera a responsabilização subjetiva.

A propósito, Miller nos lembra que Freud, em seu trabalho sobre os sonhos, pergunta-se sobre a responsabilidade subjetiva do sonhador pelos seus sonhos, inclusive aqueles de conteúdo imoral, tais como sonhos egoístas, masoquistas, cruéis, perversos, incestuosos, etc. A resposta freudiana é afirmativa (somos responsáveis pelos desejos imorais presente nos nossos sonhos), uma vez que o imoral é uma parte de nosso ser; somos feitos não somente de honras, mas também de horror. Diríamos, com Freud, que somos criminosos inconscientes e que isso aflora na consciência como sentimento de culpa. E, de modo ainda mais radical, Miller enfatiza que, para a psicanálise, "Toda consciência moral e a elaboração teórica e prática do discurso do direito são reações ao mal que cada um percebe em seu id (isso)" (Miller, 2008).

Em vista disso, em que pese encontrarmos em Foucault a proposta de um resgate da dimensão trágica da loucura (tal como ele o faz em seu livro Doença mental e Psicologia), como tratamento possível da normativização e patologização psiquiátricas, gostaria de indagar se o trágico em Foucault alcançaria a radicalidade da formulação freudiana de um sujeito dividido contra si mesmo, divisão com a qual a psicanálise introduz o campo do gozo e abre questôes clínicas, pautadas pela ética.

Não é sem interesse observar que a estratégia foucaultiana (de resgate da dimensão trágica como questionamento e ultrapassagem da normatização disciplinar), é também a do psicanalista Jacques Lacan no final dos anos 60 e 
início dos anos 70, mais precisamente nos seus seminários $A$ ética da psicanálise (1959-1960) e A transferência (1960-1961), nos quais ele se serve da tragédia antiga de Sófocles, com a releitura de Antígona (1959-1960), e da tragédia moderna, com a releitura da trilogia dos Coûfontaine, de Paul Claudel (19601961), como meios de promover um retorno a Freud, volta que visa a resgatar a psicanálise da leitura ortopédica operada pelos pós-freudianos. No entanto, nessa mesma época, ao comentar a tragédia Édipo Rei, de Sófocles, Lacan observa que ela "[...] não pode manter-se indefinidamente em cartaz nas formas de sociedade nas quais se perde cada vez mais o sentido da tragédia” (Lacan, 1998, p. 827).

Torna-se importante observar que, se a psicanálise freudiana nasce em uma época disciplinar, tal como a denomina Foucault, e se a psicanálise lacaniana se vale do recurso ao trágico para resgatar a virulência do inconsciente freudiano, ela não se detém aí. O ensino de Lacan, na década de 1970, introduz outros recursos e formulações que nos permitem problematizar os modos de funcionamento da sociedade contemporânea, essa que parece ter retirado (as considerações sobre) a dimensão trágica do seu horizonte.

Jacques-Alain Miller, em algumas conferências realizadas, em 2002, em Milão, intituladas Intuiçôes milanesas, contrapôs a sociedade disciplinar, tal como formulada por Foucault, na qual a dominação era imanente ao campo social, a uma sociedade globalizada na qual a comunicação ou informação circula por redes flexíveis, moduláveis e flutuantes, sociedade na qual a dominação não é mais externa do que interna. Para ele, a sociedade disciplinar nos diz de uma

Época em que há uma exterioridade entre os dispositivos e aparelhos de repressão e de formação, e os submetidos; nela se distingue a dominação como tal, a doutrinação que permite uma oposição frontal e a delimitação da figura dos opressores. A resistência pode então se apoiar nas formas de coerção. Foucault percorreu estes aparelhos - prisão, asilo, hospital, escola, universidade - em que vigiar e punir supõe uma clara delimitação entre o in e o out (Miller, 2011).

Miller recorre então à obra de Michael Hardt e Antônio Negri, Império, para observar que a nova ordem, essa introduzida pela globalização, coloca-nos diante de "Um mundo sem operadores, um império que não é mais de ninguém, que está por toda parte, nenhuma parte, e ao mesmo tempo sem fronteiras, sem exterior" (Miller, 2011). Com isso, evidencia-se que, de algum modo, a perda do sentido da tragédia não deixa de nos colocar diante do enfraquecimento, senão do declínio, das normas e dos ideais. Com o apagamento definitivo das normas, conclui Miller, abandona-se o que poderia reter a psicanálise na época disciplinar, reformulando-a em termos de gozo. Com isso, abre-se o espaço para a invenção sexual, a criação fora da norma, etc. Constatamos que isso não será 
sem consequências, inclusive clínicas: o final do tratamento analítico deixa de estar à mercê da transcendência, do atravessamento, e a ênfase desloca-se para as mudanças de regimes de gozo, uma vez que a satisfação pulsional se torna uma referência (Miller, 2011).

$\mathrm{Na}$ genealogia foucaultiana, fundada em uma lógica disciplinar, observamos como argumento central a existência onipotente e poderosa de um grande Outro (encarnado no psiquiatra, no legista, na família e, enfim, até no psicanalista!) que, ao ganhar muita consistência, acaba poupando o sujeito de se encontrar com sua própria divisão subjetiva, com o fato de que ele goza contra ele mesmo!

\section{CONSIDERAÇÕES FINAIS}

Isto posto, para finalizar, gostaria de fazer uma pequena confissão. Ao dormir, depois de um dia inteiro às voltas com os anormais foucaultianos, tive um sonho que me pareceu um tanto enigmático. Nele, eu estava em análise com Castel, Robert Castel. Obviamente, ao acordar, fiquei bastante intrigada, uma vez que Castel escreveu, na mesma época e provavelmente no mesmo horizonte no qual trabalhava Foucault, um livro denominado $O$ psicanalismo, no qual se propunha, tal como Foucault, a denunciar a neutralidade social e a assepsia política da psicanálise. No meu entender, tais questionamentos, muito vivos na década de 1970, o próprio movimento teórico, clínico e, mesmo, político da psicanálise, principalmente da psicanálise lacaniana, já os tomou em consideração e, de algum modo, respondeu-lhes: seja com a formulação do analista-cidadão, com a psicanálise aplicada à saúde mental, com a política lacaniana, etc. Tudo isso tornava ainda mais inusitado o meu sonho de estar em análise com Castel, alguém que não se apresentava como analista! Ups! Aí está o ponto, pude concluir: o que tanto Foucault quanto Castel parecem desconhecer, ou não levar em conta, é exatamente a psicanálise como clínica. $\mathrm{O}$ meu sonho me mostrava o impossível, a impossibilidade do discurso clínico no horizonte foucaultiano. Localizo aí o perigo, o belo perigo de Foucault: a não consideração de que o tratamento analítico é uma demanda que parte da voz daquele que sofre, em seu ser, em seu corpo, em seus pensamentos, etc.

No entanto, se vocês me perguntassem com qual dos dois discursos, psicanalítico ou foucaultiano, eu fico, eu não hesitaria um instante em lhes dizer: fico com os dois! Declaro as minhas razões: com o discurso foucaultiano, ganhamos um impulso importante para retirarmos Charles Jouy (aquele personagem de irônico nome!) do asilo, depois de o termos deixado lá por quase um século e meio; no entanto, creio que é também fundamental lhe franquearmos a possibilidade de questionar e, até mesmo, se possível, atravessar a sua identificação à posição de rebotalho, de "idiota da aldeia". Isso não ocorre sem trabalho clínico! 


\section{REFERÊNCIAS}

Castel, R. (1978). O psicanalismo. Rio de Janeiro: Graal.

Freud, S. (1929). O mal-estar na civilização. In J. Salomão (Trad.), Edição standard brasileira das obras psicológicas completas de Sigmund Freud (pp. 75171). Rio de Janeiro: Imago, 1974. (Publicado originalmente em 1929).

Foucault, M. (1968). Doença mentale Psicologia. Rio de Janeiro: Tempo Brasileiro.

Foucault, M. (2010). Os anormais. São Paulo: Martins Fontes.

Lacan, J. (1959-1960). O Seminário, livro 8. A transferência. Rio de Janeiro: Jorge Zahar, 1992. (Publicado originalmente em 1959-1960)

Lacan, J. (1960-1961). O Seminário, livro 7. A ética da psicanálise. Rio de Janeiro: Jorge Zahar, 1988. (Publicado originalmente em 1960-1961)

Lacan, J. (1960). Subversão do sujeito e dialética do desejo no inconsciente freudiano. In J. Lacan, Escritos (pp. 807-842). Rio de Janeiro: Jorge Zahar, 1998. (Publicado originalmente em 1960).

Miller, J.-A. (2008). Nada é mais humano do que o crime. Almanaque: Revista Eletrônica do IPSM-MG, 4. Recuperado a partir de http://almanaquepsicanalise. com.br/wp-content/uploads/2015/09/Nada-mais-humano-que-o-crime.pdf

Miller, J.-A. (2011, julho). Intuições milanesas. Opção Lacaniana: nova série, 2(5). Recuperado a partir de http://www.opcaolacaniana.com.br/pdf/numero_5/ Intuições_milanesas.pdf 